\title{
Partnerships in Translation: Advancing Research and Clinical Care. The 14th Annual HMO Research Network Conference, April 13-16, 2008, Minneapolis, Minnesota
}

Robert T. Greenlee, PhD, MPH; Laura A. Coleman, PhD; Andrew F. Nelson, MPH; and Joseph V. Selby, MD, MPH

\begin{abstract}
The Health Maintenance Organization Research Network held its annual meeting in Minneapolis in April of 2008, with more than 300 investigators, research staff, clinical leaders, and academic partners gathering in conjunction with the conference theme 'Partnerships in Translation: Advancing Research and Clinical Care.' This article provides some background on the network, its research activities, and the annual conference. Also featured is an article by Coleman and colleagues summarizing the conference's first plenary session, where operational leaders of health care organizations discussed the optimization of health care through research. This issue of Clinical Medicine \& Research also includes a selection of scientific abstracts presented at the meeting on a wide range of clinical and population health topics.
\end{abstract}

Keywords: Integrated delivery of health care; Managed care programs; Multicenter study

\begin{abstract}
A reports on scholarly activity not only within the broad topics of medical research and clinical care, but also on the junction between them. The functionality of this intersection is viewed by many as one of the critical factors that can drive, or hinder, needed improvements in patient health and the state of our health care system. ${ }^{1}$ In April 2008, an organization that shares interest in the crucial connection between research and practice, the Health Maintenance Organization Research Network (HMORN), held their 14th annual conference in Minneapolis. The HMORN is a consortium of research programs that are integrated with health care delivery systems and health maintenance organizations. The network's overall goal is to 'transform health care practice through population-based research to improve the health and health care of broad populations.' ${ }^{2}$ This issue of Clinical Medicine \& Research features select proceedings from that conference.
\end{abstract}

The network was formed in 1994 and has grown to include 15 geographically diverse organizations (figure 1) that are

Reprint Requests: Robert T. Greenlee, PhD, MPH, Epidemiology Research Center, Marshfield Clinic Research Foundation, 1000 North Oak Avenue Marshfield, WI 54449, Tel: 7I5 389-3537, Fax: 7I5-389-3880, E-mail: greenlee.robert@mcrf.mfldclin.edu committed to advancing population health through public domain research. ${ }^{3}$ These organizations manage and provide health care for more than 11 million patients and capture clinical data in electronic medical record systems. Over 200 HMORN investigators foster research collaboration across the network and with external stakeholders using these large, defined populations and research data resources.

The HMORN has been meeting annually since 1995 . The conferences not only provide a platform to promote recent research findings, but they also serve as fertile ground for development of new ideas, consideration of new partnerships, and exploration of innovative tools and methods to support new research. Over time, the HMORN has leveraged its unique capacities and established a number of topic-specific research consortia to address critical research questions within the context of health care delivery and 'real world' patient populations (table 1). ${ }^{5-11}$ The 2008 meeting was co-hosted by HealthPartners Research Foundation and Marshfield Clinic Research Foundation. Consistent with the conference theme, Partnerships in

Received: November 18, 2008 doi: $10.3121 / \mathrm{cmr} .2008 .842$

Authors, Robert Greenlee and Andrew Nelson, were co-hosts of the 2008 HMO Research Network Annual Meeting. 


\section{HMO Research Network Members}

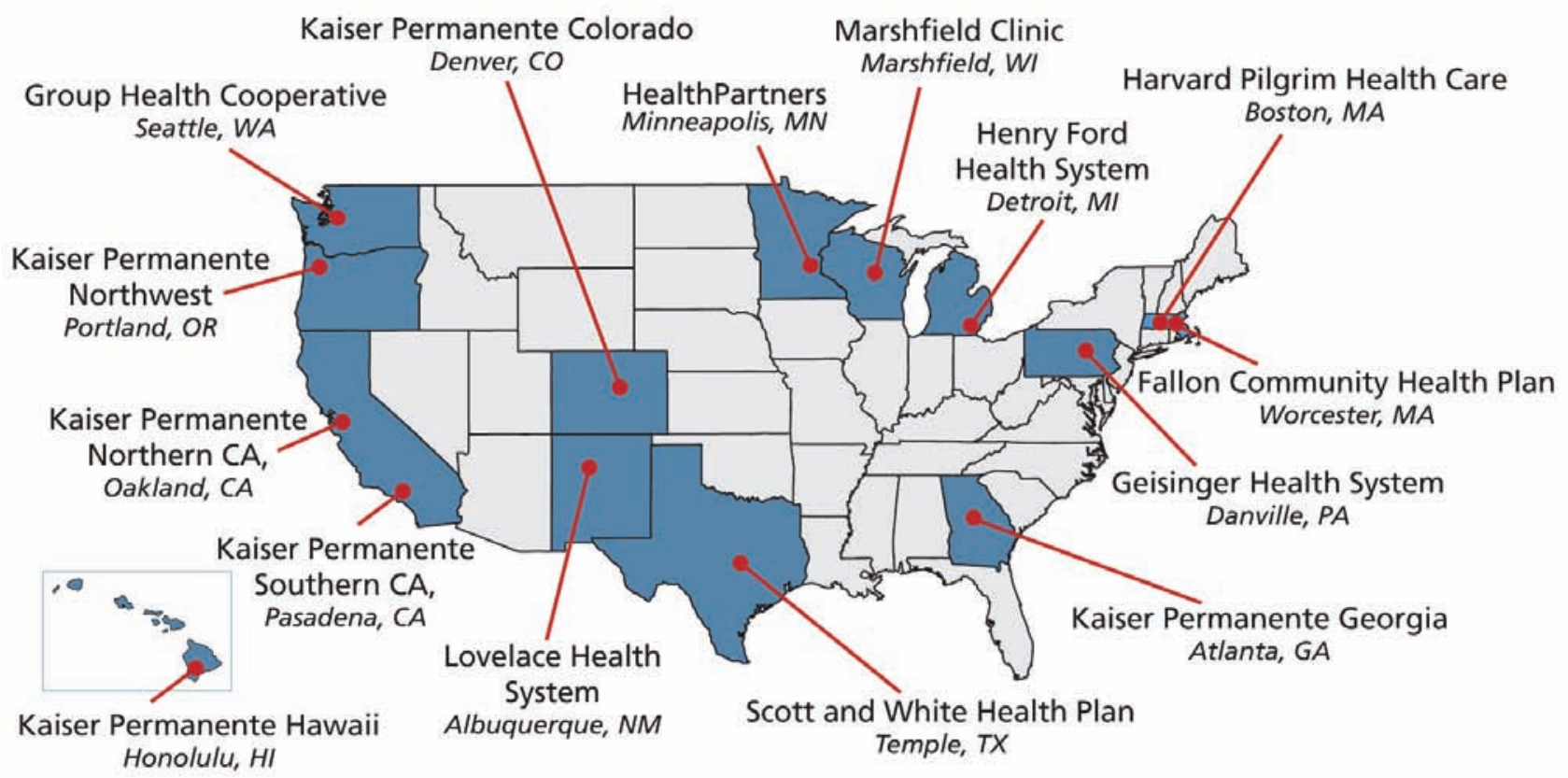

Figure 1. Map of Health Maintenance Organization Research Network member locations.

Translation: Advancing Research and Clinical Care, this conference reached beyond the formal HMORN and attracted additional collaborators to share experiences, discuss tools and technologies, expand opportunities for productive partnerships, and provide evidence to support health research funding and public policy decisions. Approximately 300 attended, including researchers and operational leaders from HMORN organizations; representatives from two prospective HMORN member organizations; the National Cancer Institute, the Centers for Disease Control and Prevention, and three other federal agencies; and more than a dozen academic centers interested in developing or expanding collaborations.

In the meeting's plenary sessions, expert panels provided engaging discussion of three forward-looking partnerships: (1) health care delivery systems and research organizations as partners to optimize health and health care, (2) linking electronic medical records, distributed networks, analytic capabilities, and novel statistical methods to create critical public health surveillance systems, and (3) research organizations and academic institutions working together to achieve the full potential of translational research. Dr. Barbara Alving, director of the National Center for Research Resources and leader of the federal Clinical and Translational Science Award (CTSA) program, was a keynote speaker for the translational research plenary panel.

The meeting agenda also included two scientific poster sessions and 16 concurrent sessions with oral abstract presentations across a wide range of important topics, including research administration, pharmacoepidemiology, health disparities, obesity, cancer, analytic methods, behavioral interventions, diabetes, health economics, cardiovascular disease, informatics, quality improvement, and a session for junior investigators showcasing a grant proposal study section mock review. Nearly 170 scientific presentations were featured in both oral and poster format.

Importantly, there were more than 30 ancillary sessions on the formal agenda, most of which reflected new or developing partnerships focused on critical topics such as translational science, health literacy, patient-centered communication, obesity, ovarian cancer, biobanking, pharmacogenetics, sexually transmitted diseases, maternal morbidity, and cancer control interventions. Sessions were also held on research support, grant writing, federal reporting, collaboration with comprehensive cancer centers, increasing participation in clinical trials, and several sessions on technologies for standardized data development, data sharing, natural language processing, and new approaches for collection of family history data.

In addition to a CTSA plenary panel devoted to community research/academic partnerships, a special discussion session was held on behalf of attending academic partners focused on collaborating to enhance expertise and capacity to study community care within defined populations. This 3 hour facilitated discussion was convened with 10 CTSA academic health center awardees/applicants, their respective HMORN research organization partners, several additional HMORN members, and Dr. Alving. 
One of the annual meeting highlights is the State of the Network address delivered by the current chair of the network Governing Board. The 2008 address was presented by Joe Selby, MD, MPH, director of the Division of Research at Kaiser Permanente in Oakland California. In his address, Dr. Selby reported on important opportunities and challenges identified in a survey of HMORN investigators conducted in the past year. Opportunities for the network commonly identified by survey participants include: (1) using existing collaborative research projects as platforms to develop ongoing partnerships and to build infrastructures that will support future collaboration, (2) pursuing unique opportunities for outcomes and patterns of care research, (3) leveraging electronic medical record resources for research, and (4) supporting translation and diffusion research toward optimization of medical care. Important challenges were recognized as well, and these include: (1) ongoing bureaucratic and budgeting inefficiencies for multicenter projects, (2) difficulties with multicenter communications, including identifying organizational capacities and appropriate research collaborators, and (3) a perceived tension between pursuing success in collaborative work and achieving research benchmarks necessary for tenure and promotion, such as first author publications and serving as a project principal investigator.

In his address, Dr. Selby contended that the ongoing enhancement of critical network infrastructure to address these opportunities and challenges also heralds a maturing of the 14-year-old collaborative research network. An active group of network leaders comprising the HMORN's Assets Stewardship Committee were acknowledged as having envisioned the way forward for many of these new developments. For instance, committed efforts of network site representatives have supported growing efficiencies in both multicenter research administration and the processes for Institutional Review Board review and approval. An extensive collaboration toolkit, available through the HMORN website, ${ }^{12}$ has been developed to facilitate new research collaborations within and beyond the network. One key resource of the HMORN, a federated, standardized data repository at each participating institution known as the virtual data warehouse (VDW), is receiving extensive attention through a new VDW Operations Committee, with a series of data development and quality assurance working groups formed by investigators, data managers, and other programming staff from around the network. Related policies for data sharing and for the sustainable financial infrastructure to support this evolution are under development within the network's Governing Board.

Dr. Selby indicated that the observed progress is occurring against the backdrop of a remarkable point in the network's history, with nearly all HMORN members involved with academic partners in either funded or proposed CTSA programs from the National Institutes of Health (NIH). Further, the HMORN is being sought as a partner of choice for many of the institutes within NIH and other federal research agencies due to its intellectual capital — its capacities to work with population-wide medical care data, and its researchers that have the experience to develop and use relevant knowledge.

A summary of the session would not be complete without reporting the tribute awarded this year to Martin L. Brown, $\mathrm{PhD}$, Chief of the Health Services and Economics Branch in the Applied Research Program of the National Cancer Institute's Division of Cancer Control and Population Sciences. Dr. Brown received the formal appreciation of a grateful research network for his vision, long-term support, and ongoing collaboration that has had an irreplaceable impact on the HMORN. Finally, Dr. Walter (Buzz) Stewart of Geisinger Health System invited all attendees to the $15^{\text {th }}$ Annual HMORN conference to be held in April 2009 in Danville, Pennsylvania.

In this issue of Clinical Medicine \& Research, readers can familiarize themselves further with capacities and interests of HMORN investigators by reviewing a selection of scientific abstracts presented in concurrent and poster sessions at the meeting. Also, the kickoff plenary session, which directly addressed the critical junction between research and medical practice through a panel discussion of clinical leaders from three of the network's health care organizations, is summarized in an article by Coleman and colleagues. ${ }^{13}$ Summaries of the conference's other two plenary sessions on partnerships for disease surveillance and partnerships for clinical and translational science are in development for publication elsewhere.

Table 1. Large federally-funded research collaborations, Health Maintenance Organization Research Network.

- Cancer Care Outcomes Research and Surveillance Consortium, National Cancer Institute ${ }^{4}$

- Cancer Research Network, National Cancer Institute ${ }^{5}$

- Cardiovascular Research Network, National Heart, Lung, and Blood Institute ${ }^{6}$

- Coordinated Clinical Studies Network, National Institutes of Health Roadmap ${ }^{7}$

- Vaccine Safety Datalink, Centers for Disease Control and Prevention ${ }^{8}$

- Centers for Education and Research in Therapeutics, Agency for Healthcare Research and Quality ${ }^{9}$

- Developing Evidence to Improve Decisions about Effectiveness Network, Agency for Healthcare Research and Quality ${ }^{10}$

- Integrated Delivery System Research Network, Agency for Healthcare Research and Quality ${ }^{11}$

- Research consortia for epidemiologic studies of adverse effects of marketed drugs, Food and Drug Administration ${ }^{7}$ 


\section{Acknowledgments}

The 2008 HMO Research Network Annual Meeting was made possible in part by grants from the Agency for Healthcare Research and Quality (1R13HS017518-01) and the National Cancer Institute (1R13CA128384-02), and by HealthPartners, HealthPartners Research Foundation, HealthPartners Medical Group \& Clinics, Marshfield Clinic Research Foundation, Marshfield Clinic, and Security Health Plan. The views expressed in written conference materials or publications and by speakers and moderators do not necessarily reflect the official policies of the Department of Health and Human Services, nor does mention by trade names, commercial practices, or organizations imply endorsement by the US Government.

\section{References}

1. Lenfant C. Shattuck lecture-clinical research to clinical practice-lost in translation? N Engl J Med 2003; 349:868-874.

2. The HMO Research Network (brochure). 2008. Available at: http://www.hmoresearchnetwork.org/resources/tools/ HMORN_Brochure.pdf. Accessed October 2008.

3. Vogt TM, Elston-Lafata J, Tolsma D, Greene SM. The role of research in integrated healthcare systems: the HMO Research Network. Am J Manag Care 2004;10:643-648.

4. Ayanian JZ, Chrischilles EA, Fletcher RH, Fouad MN, Harrington DP, Kahn KL, Kiefe CI, Lipscomb J, Malin JL, Potosky AL, Provenzale DT, Sandler RS, van Ryn M, Wallace RB, Weeks JC, West DW. Understanding cancer treatment and outcomes: the Cancer Care Outcomes Research and Surveillance Consortium. J Clin Oncol 2004;22:2992-2996.

5. Wagner E, Greene SM, Hart G, Field TS, Fletcher S, Geiger AM, Herrinton LJ, Hornbrook MC, Johnson CC, Mouchawar J, Rolnick SJ, Stevens VJ, Taplin SH, Tolsma D, Vogt TM. Building a research consortium of large health systems: the Cancer Research Network. J Natl Cancer Inst Monogr 2005;(35):3-11.

6. Magid DJ, Gurwitz JH, Rumsfeld JS, Go AS. Creating a research data network for cardiovascular disease: the CVRN. Expert Rev Cardiovasc Ther 2008;6:1043-1045.

7. HMO Research Network. Research projects. Intellectual collaboration is the foundation of the HMO Research Network. http://www.hmoresearchnetwork.org/projects.htm. Accessed October 2008.

8. Chen RT, Glasser J, Rhodes P, Davis RL, Barlow WE, Thompson RS, Mullooly JP, Black SB, Shinefield HR, Vadheim CM, Marcy SM, Ward JI, Wise RP, Wassilak SG, Hadler SC. Vaccine Safety Datalink project: a new tool for improving vaccine safety monitoring in the United States. The Vaccine Safety Datalink Team. Pediatrics 1997;99:765-773.

9. Platt R, Davis R, Finkelstein J, Go AS, Gurwitz JH, Roblin D, Soumerai S, Ross-Degnan D, Andrade S, Goodman MJ, Martinson B, Raebel MA, Smith D, Ulcickas-Yood M, Chan KA. Multicenter epidemiologic and health services research on therapeutics in the HMO Research Network Center for Education and Research on Therapeutics. Pharmacoepidemiol Drug Saf 2001;10:373-377.

10. Agency for Healthcare Research and Quality. Generate knowledge (DEcIDEs). Available at: http:// effectivehealthcare.ahrq.gov/aboutUs.cfm? abouttype $=\mathrm{d}$ ecidecert\#DecideList. Accessed October 2008.
11. Agency for Healthcare Research and Quality. Integrated Delivery System Research Network (IDSRN). Available at: http://www.ahrq.gov/RESEARCH/idsrn.htm. Accessed October 2008.

12. HMORN Collaboration Toolkit. A guide to multi-site research. Available at:

http://www.hmoresearchnetwork.org/resources/toolkit/ HMORN_CollaborationToolkit.pdf. Accessed October 2008.

13. Coleman LA, Kottke TE, Rank B, Reding DJ, Selna M, Isham GJ, Nelson AF, Greenlee RT. Partnering care delivery and research to optimize health. Clin Med Res 2008;6:113-118.

\section{Author Affiliations}

Robert T. Greenlee, PhD, MPH

Epidemiology Research Center

Marshfield Clinic Research Foundation

Marshfield, Wisconsin 54449

Laura A. Coleman, PhD

Marshfield Clinic Research Foundation

Marshfield, Wisconsin 54449

Andrew F. Nelson, MPH

HealthPartners Research Foundation

Minneapolis, Minnesota 55440

Joseph V. Selby, MD, MPH

Division of Research

Kaiser Permanente Northern California

Oakland, California 94612 